\title{
Experimental Method in Industrial Relations
}

$\mathrm{A}^{\mathrm{N}}$ $\mathrm{N}$.interesting discussion arranged by the Department of Industrial Co-operation of Section $\mathbf{F}$ (Economic Science and Statistics) at the Aberdeen meeting of the British Association dealt with the use of the experimental method in the field of industrial relations. It would probably have attracted more attention had it not been postponed to the last morning of the meeting.

The three papers forming the basis of the discussion were all highly stimulating and suggestive. Mr. M. H. Dubreuil's paper on autonomous groups in industry was essentially a plea for greater delegation of responsibilities in indústry as a means of associating the workers with the success of the business which employs them. M. Dubreuil pointed out that this involves the discovery of responsibilities in accordance with the character and extent of the special abilities of the worker, and not in accordance with the abilities possessed by persons in the business entrusted with quite different tasks. The secret of scientific progress in' the internal organisation of work lies in these terms of differentiated abilities.

Many problems of equipment, distribution of work, supplies, processes, etc., outside the scope of the abilities of the general manager could usefully be appreciated by the workman, and M. Dubreuil envisaged the subdivision of the business into relatively autonomous groups corresponding to the various tasks revealed by analysis of its technical structure. To this technical subdivision might be added a subdivision of the general budget, so that members of each group might act as if they really formed an independent business, thus ensuring an interest in the profit ensured by the good management of the fraction of the budget entrusted to them. M. Dubreuil believes that organisation of work on these lines is to be preferred to many profit-sharing systems.

This plea for experimental study of the structure of industrial organisation was followed by another striking paper, by Prof. F. Meyenberg, on the improvements in industrial relations arising from the intervention of the management consultant. Prof. Meyenberg pointed out that the independent consultant possesses definite advantages. $\mathrm{He}$ is not tied to a daily routine and can give his whole time to questions of organisation. Being free from departmental bias, he can keep in view the harmony of the whole organisation. Moreover, his experience in different branches of industry makes it easier for him to recognise common principles and to avoid undue attention to relatively unimportant details.
In addition, since such a consultant is concerned primarily with the large field of management and not with questions of technology or production, any essential knowledge of the particular trade required to avoid difficulty in the introduction of management methods can easily be acquired by a man of the ordinary technical education essential for any consultant. These advantages and the freedom from the deadening effect of tradition on those who have spent long years in an industry give the management consultant a wide sphere of service in industry which is far from being generally appreciated or utilised.

In Prof. Meyenberg's opinion, some of the prejudice against the use of an outside consultant is due to the fact that the wrong man has sometimes been called in. This is probably a less important factor than the conservatism of the average industrialist, but the importance of the quality of the consultant needs no emphasis. Prof. Meyenberg made the further suggestion that such consultants might be recruited from the captains of industry themselves.

The third of the three papers, that of Mr. R. J. Mackay, was concerned with experiments in readjustment of relations between finance-capital, management and operative labour. Mr. Mackay pleaded for experiments in reversal of the customary relations between absentee owners and working personnel, such that capital will only be attracted if the capitalist has confidence in the efficiency of the team which desires to hire his capital. Among other rather revolutionary suggestions in an admirable plea for the improvement of the relations between capital, management and labour, Mr. Mackay submitted a case for the division of medium- or largesized businesses into relatively independent responsible groups of working personnel, and indicated its bearing upon the wider utilisation of biological laboratory technique for vocational selection, guidance and placement of existing and potential industrial personnel of all qualities.

These three thoughtful papers pleading for wider use of experimental methods in studying the structure and development of industrial organisation give a highly significant picture of the wide field which industrial management offers for the use of scientific methods. The future of industry, and to a large extent the structure of society, are bound up with the application of impartial studies in this field, and the Department of Industrial Co-operation is to be congratulated once again upon the way in which it has attempted to indicate the possibilities in this direction to the British Association and to the public.

\section{American Stratosphere Ascent of July 29, I934}

BRIEF account was given in Nature of July
28,1934, p. 132, of a projected American
ascent into the stratosphere in the balloon Explorer,
jointly organised by the National Geographic Society
and the U.S. Army Air Corps. The following week
it had to be recorded that the flight had failed, but
that the pilot, Major W. E. Kepner, the observer,
Capt. A. W. Stevens, and the alternate pilot, Capt.
O. A. Anderson, had escaped by parachute from the
falling balloon. Most of the valuable instruments were completely destroyed; but it would now appear that many of the records made on photographic strip have been saved.

Some of these results have recently been described in London at the International Conference on Physics in a contribution by Bowen, Millikan and Neher, while in the National Geographic Magazine of October Capt. Stevens contributes an article on the general aspects of the flight from which some further ideas of the faultless organisation and mechanical skill of 
the enterprise may be obtained. The whole was a triumph of self-registration devices. Contributions of instruments were made by educational and other institutions in many parts of the United States. There were tubes of spore cultures, three spectrographs, one for ozone, one for sky and one for horizon ; three electroscopes for cosmic ray ionisation, one exposed, one inside 4 in. of lead shielding and another weighing $600 \mathrm{lb}$. with a 6 in. covering of lead. These were contributed by Millikan and Neher. A contribution by Swann and Locher was a counter apparatus arranged for recording cosmic ray intensity from four different directions from the vertical to the horizontal. There were coarse and inter-range barometers for recording pressure variations automatically at high altitudes, and a dozen or more parachutes for men, heavy instruments and gondola.

Besides a perfect barograph record of the event which shows that a minimum pressure of $60 \mathrm{~mm}$. was reached, electroscope records of cosmic ray ionisation from ground-level to $60,000 \mathrm{ft}$. were obtained. These have led Millikan to the conclusion that the only source of the observed cosmic ray energies now in sight is matter annihilation : most of the ionisation observed at sea-level is due to incoming photons produced during the destruction of matter in higher altitudes. Records of sun and sky brightness, internal and external temperature, the altitude of the inversion of the temperature gradient between $20,000 \mathrm{ft}$. and $38,000 \mathrm{ft}$., were also obtained. Capt. Stevens concludes by saying, "our most eheering thought of the recent ascent is that we feel we have successfully solved the problems of living and working efficiently in the stratosphere . . . not a single piece of scientific equipment attached to the gondola failed us during the flight ; every instrument worked exactly as planned".

The mishap was due to a rip in the lower part of the balloon which was first noticed at the highest altitude. The men owe their lives to the perfection of the carefully designed scalloped band attached to the balloon fabric to which the gondola was roped. This band held the balloon steady in a drop of about $55,000 \mathrm{ft}$. in about $1 \frac{1}{2}$ hours and kept the rips from extending.

\section{Inheritance of Anatomical Structure in Plants}

$\mathrm{T}$ HERE have been very few investigations of the inheritance of anatomical structure in plants. A recently issued work by $\mathrm{E}$. W. Sinnott, Helen Houghtaling and A. F. Blakeslee* is a contribution to this subject, based on a comparison of the vascular anatomy in, $(a)$ the polyploid forms of Datura $(n, 2 n$, $3 n, 4 n)$, and $(b)$ the 12 trisomic $(2 n+1)$ mutants and such of their secondaries as were available. Among the few earlier studies, the authors have overlooked the work of Penhallow on the anatomy of a hybrid Catalpa, and the papers of Gates and Bartlett on cell measurements in tetraploid Enothera.

The flower pedicel was chosen for anatomical study, as comparable material could most easily be obtained from this region. Seventeen anatomical traits of this structure were quantitatively studied. In the polyploid series, as in previous results, there was progressive increase in size of the structure and its constituent cells, but not always in the proportion

* The Comparative Anatomy of Extra-Chromosomal Types in Datura stramonium. By Edmund W. Sinnott, Helen Houghtaling plates. (Washington, D.C.: Carnegie Institution, 1934.) expected. The cortex was relatively large in the haploid, and relatively small in the $3 n$ and $4 n$ mutants, the smaller cortex being due to fewer cells. These facts, and others from the heteroploid series, lead to the conclusion that cell size and cell number are independently controlled.

There were certain exceptions to the increasing cell size in the polyploid series. The pericycle fibres remain of the same size, perhaps because they are frequently found to be multinucleate. The leaves increase in thickness, due to increase in cell size and elongation of the palisade cells, those of the tetraploid having at least twelve times the volume of those in the haploid. Similarly the petiole in cross-section is about sixteen times as large in the tetraploid as in the haploid, the same applying generally to the cells, which therefore show a geometric rather than an arithmetic ratio of increase.

In the heteroploid series, all having 25 chromosomes, the anatomical differences were equally marked and were due to the genic constitution of the extra chromosome. Certain of the primaries, such as 'spinach', were even larger than the tetraploid, this being due almost entirely to larger cell size. Different elements of the anatomy show considerable independence in their response to the presence of specific chromosomes. The conception of genic balance applies very well to some of the secondaries in comparison with their primaries, but this is by no means always the case, and various attempts are made to explain aberrant results. Curious facts which emerge are that the starch grains, especially in the secondaries, may have a very large or very small mean size, and that while the style of the flower has two vascular bundles in the $2 n, 3 n$ and $4 n$ forms, in the haploid it always has five or six.

\section{University and Educational Intelligence}

Cambridge.-Prof. R. H. Tawney, of the University of London, has been appointed Alfred Marshall lecturer for 1934-35.

Dr. T. S. Hele has been appointed assessor to the Regius professor of physic.

Trinity College announces the offer of a research studentship open to graduates of other universities who propose to go to Cambridge in October next as candidates for the degree of Ph.D. Dominion and Colonial exhibitions are also offered to students of Dominion and Colonial universities who wish to go to Cambridge next October as candidates for the degree of B.A., M.Litt., M.Sc., or Ph.D. Further information can be obtained from the Senior Tutor, and applications should reach him by July 1, 1935.

MANCHESTER.-In connexion with the meeting of the Chemical Society to be held in the University on November 9 and 10, a reunion dinner of past and present members of the Department of Chemistry has been arranged; arrangements are in the hands of Drs. G. N. Burkhardt and C. E. H. Bawn of the Chemistry Department. A party of a hundred fellows of the Chemical Society will visit the Shirley Institute of the British Cotton Industry Research Association on November 9.

The following resignations and appointments have been announced this session :-Mr. F. W. Priestley has been appointed lecturer in veterinary bacteriology in succession to Mr. C. A. MeGaughey, resigned. Dr. 